\section{Digestive Diseases}

Abuksis, G. 253

Arnold, R. 246

Axon, A. 220, 242, 271, 280

Barbatzas, C. 289

Bassi, A. 275

Bodger, K. 275

Brown, E. 275

Christodoulou, G. 289

Escourrou, J. 257

Farthing, M.J.G. 230

Fourtanier, G. 257

Hadziyannis, S. 284
Hatziargyriou, M. 289

Isaacs, P.E.T. 226

Kapoor, N. 275

Keighley, M. 246

Koskinas, J. 284

Kruse, A. 271, 280

Ladas, S.D. 209, 242, 271, 280, 289

Lambert, R. 236

Liappas, I. 289

Livadas, G. 216

Malfertheiner, P. 242, 266, 271, 280

Manesis, E. 284
Merkouraki, P. 284

Niv, Y. 253

Raptis, S.A. 289

Rey, J.F. 236

Reymond, M.A. 257

Sommerville, A. 210

Stanciu, C. 271, 280

Steinert, R. 257

Treiber, G. 266

Triantafyllou, K. 271, 280, 289

Tzavellas, E. 289

\title{
Subject Index Vol. 20, No. 3-4, 2002
}

Adverse effects 284

Autonomy 210

Beneficence 210

Bioethics 210

Chronic viral hepatitis 284

Colonoscopy 236, 246

Colorectal cancer 246

Committee on Publication Ethics 230

Complications of endoscopy 226

Consent 275

Decision making 289

Depression 284

Diagnostic endoscopy 236

Doctor-patient relationship 226

Documentation 280

Dysphagia 289

Eating disorder 289

Economics 246

Education 271

Endoscopy 220, 226, 266, 271, 275, 280

- indications 236

- simulators 242

- training curriculum 242
Ethical aspects 253

Ethics 210, 246, 257, 266, 275, 289

- committee 271

- in endoscopy 242

European Society of Gastrointestinal Endoscopy 271, 280

Fecal occult blood test screening 246

Fraud 230

Gastroenterology 220, 271, 280

Gastroscopy 236

Healthy volunteers 266

Hippocrates 226

Hippocratic values 210

Human tissue 257

Indications 266

Information 280

Informed consent 226, 242, 280

Interferon 284

Law 280

Learning endoscopy 242

Legal and economic issues 257

Limitations 266

Low-risk population 246
Medical ethics 216, 220, 226

- negligence 242

Medicolegal procedures 275

Mortality 216

Nutritional support 289

Patient expectations 220

Peer-review 230

Percutaneous endoscopic gastrostomy 253, 289

Physician roles 220

Postgenomic research 257

Purpose 271

Redundant publication 230

Research 266

- ethics 230

Sigmoidoscopy 246

Socioeconomic issues 216

Surveillance 236

Teaching endoscopy 242

Values 210

\section{KARGER}

(C) 2002 S. Karger AG, Basel

Fax +4161306 1234

E-Mail karger@karger.ch

www.karger.com
Accessible online at: www. karger.com/ddi 